\title{
REFORMA DA EDUCAÇÃO SUPERIOR: UM ESTADO DA ARTE
}

\author{
Reform of higher education: one state of art
}

Reforma de la educación superior: un estado del arte

\begin{abstract}
Não existe organização sem intelectuais, isto é, sem organizadores e dirigentes, ou seja, sem que o aspecto teórico da ligação teoria-prática se distinga concretamente em um estrato de pessoas "especializadas" na elaboração conceitual e filosófica. Antonio Gramsci (1999, p. 104).
\end{abstract}

RESUMO O presente estudo "Reforma da Educação Superior: um estado da arte" tem como objeto os textos veiculados em revistas científicas no período entre 2003 e 2013 e critica o quantitativismo dos chamados estados da arte, defendendo ser inócua a separação das quantidades das qualidades, na medida em que isto situa o conhecimento na periferia do ato histórico central. Com rigorosa atenção ao materialismo histórico dialético, o seu objetivo é o de trazer à luz não as quantidades de textos publicados, mas as concepções de mundo que os seus autores e comentaristas pretendem cimentar e unificar em dado bloco social e captar o sentido do movimento que fazem, o seu impacto em termos de construção de novos tempos e as alterações que são capazes de promover para privilegiar as concepções que elegem. Este texto, produzido em bases marxistas, portanto, se propõe a ir para além dos inventários feitos pelos estados de arte comuns. PALAVRAS-CHAVE: EdUCAÇÃO SUPERIOR, REFORMA DA UNIVERSIDADE, ESTADO DA ARTE

ABSTRACT The present study "Reform of Higher Education: one states of art" has as its object the texts published in scientific journals in the period between 2003 and 2013 and criticizes the quantitative nature of the so-called states of art, arguing that the separation of the quantities of the qualities is innocuous, inasmuch as this places the knowledge on the periphery of the central historical act. With rigorous attention to dialectical historical materialism, its objective is to bring to light the conceptions that its authors and commentators intend to cement and unify in each social block and capture the meaning of the movement they make, its impact in terms of construction of new times and the changes they can promote to privilege the conceptions they

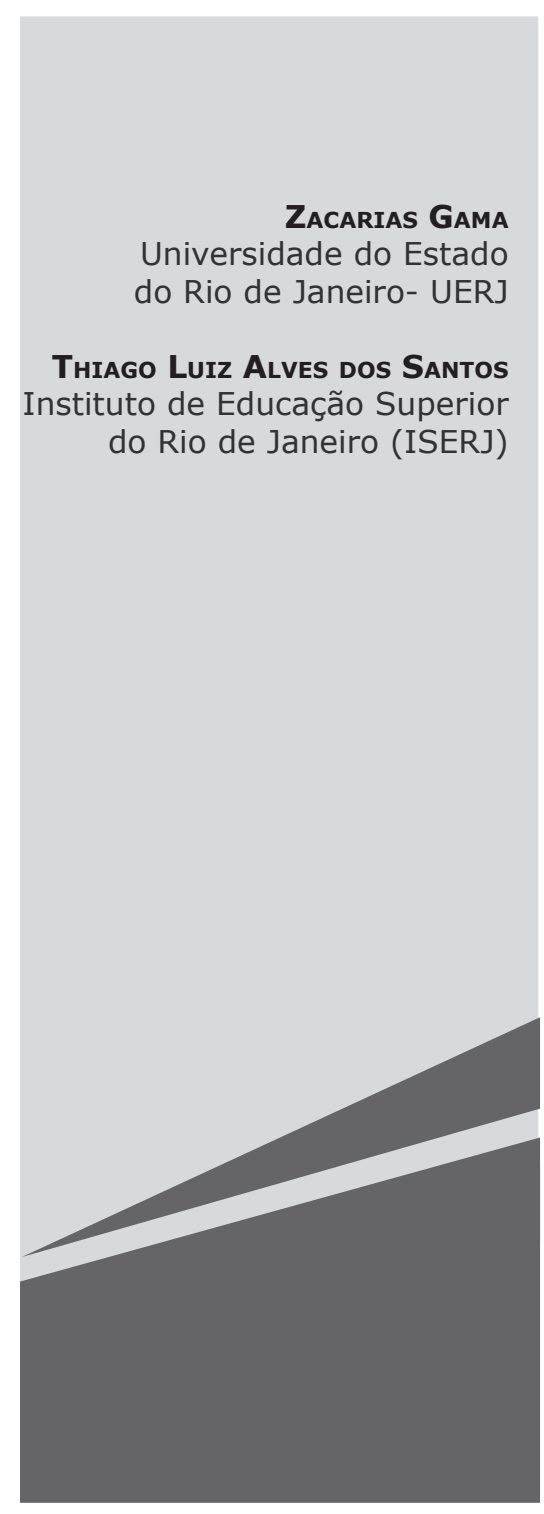


elect. The present text produced on Marxist grounds therefore proposes to go beyond the inventories made by the common states of art.

KEYWORDS: HIGHER EDUCATION, UNIVERSITY REFORM, STATE OF THE ART

RESUMEN El presente estudio "Reforma de la educación superior: un estado del arte" tiene como objeto los textos publicados en revistas científicas en el período entre 2003 y 2013 y critica el cuantitativismo de los llamados estados del arte, defendiendo que es inocua la separación de las cantidades de las calidades, en la medida en que esto sitúa conocimiento en la periferia del acto histórico central. Con una cuidadosa atención al materialismo histórico dialéctico, su objetivo es el de traer a la luz no las cantidades de textos publicados, sino las concepciones de mundo que sus autores y comentaristas pretenden cimentar y unificar en dado bloque social y captar el sentido del movimiento que hacen, su impacto en términos de construcción de nuevos tiempos y las alteraciones que son capaces de promover para privilegiar las concepciones que eligen. El presente texto producido en bases marxistas, por lo tanto, se propone ir más allá de los inventarios hechos por los estados de arte comunes.

PALABRAS CLAVE: EdUCACIÓN SUPERIOR, REFORMA UNIVERSITARIA, ESTADO DEL ARTE.

\section{INTRODUÇÃo}

A produção de estudos denominados de "Estado da Arte" ou "Estado do Conhecimento" tem sido comum na área da Educação desde o final dos anos 1980. De ordinário entre eles é o desafio de mapear, inventariar, descrever ou discutir certa produção científica em dado campo de conhecimento. Alguns desses estudos com o passar do tempo têm adquirido o status de importantes referências para a produção científica educacional. Ferreira (2002), por exemplo, Ihes deu grande destaque na produção em Educação em um texto de sua autoria publicado pela revista Educação e Sociedade. Outros intelectuais “"especializados' na elaboração conceitual e filosófica”, como disse Gramsci na epígrafe citada, também merecem destaque: Soares (1989), Fiorentini (1994), Megid (1999), Brzezinski e Garrido (1999). Mas qual o legado de tais estudos para a produção de novos conhecimentos?
É suficiente mapear, inventariar, descrever e discutir certa produção científica?

De um ponto de vista puramente quantitativo, é aceitável que muitos acolham como positiva a resposta à questão; afinal não é descabido identificar quantitativamente os textos publicados, os locais de produção, assim como catalogar a produção, descrevê-la e discuti-la. Diversos estudos de tipo quantitativo disponibilizam publicamente de forma ordenada e relevante a produção sobre determinada temática, como autênticos e imprescindíveis catálogos que são verdadeiros guias para todos os que se aventuram a investigar determinado campo e objeto de conhecimento. Mas, apenas isso é suficiente? A realidade objetiva se apresenta inteiramente por meio das quantidades? Em princípio, é certo que não, afinal, quantidade e qualidade são inseparáveis, determinam-se reciprocamente e integram a mesma unidade dialética.

Os estudos denominados de Estados da Arte, contudo, objetivamente, carecem 
ir além de inventariar quantidades de textos escritos. Superar esse momento tem grande importância porque os seus autores e comentaristas, como a epígrafe deste texto aponta, são pessoas de grande potencial para elaborações conceituais e filosóficas. Elas têm poder, por exemplo, de colocar em evidência com mais visibilidade dada concepção de mundo. Mas, para onde apontam esses mesmos autores? Isto é, qual sociabilidade pretendem construir e tornar hegemônica? O que querem massificar de maneira mais ou menos intensa para impedir ou não manifestações contrárias e favoráveis e produzir ou não estados de passividade política e moral?

Ora, os textos produzidos e veiculados em livros e periódicos científicos de grande penetração no meio acadêmico e até fora dele não são neutros ou desprovidos de valores. As temáticas, metodologias e fatos são escolhas dos cientistas-escritores que lhes dão visibilidades e eles as expõem conforme os seus interesses, valores e juízos. São, portanto, refutáveis as teses de neutralidade temática, metodológica e factual das ciências, quaisquer que sejam. Todos os cientistas são sujeitos concretos politicamente ativos, têm contas a pagar, cuidam de suas famílias e se inscrevem em determinadas relações de vizinhança, recreação, religiosidade etc. Gramsci há muito já indicara a consciência contraditória deles:

É quase possível dizer que ele [o autor] tem duas consciências teóricas (ou uma consciência contraditória): uma implícita na sua ação, e que realmente o une a todos os seus colaboradores na transformação prática da realidade; e outra, superficialmente explícita ou verbal, que ele herdou do passado e acolheu sem crítica (GRAMSCl, 1999, p. 103).

Tendencialmente os autores agem como intelectuais organicamente ligados a determinados grupos sociais. Cada grupo social, como Gramsci já disse, cria as suas "camadas de intelectuais" que "Ihes dão homogeneidade e consciência da própria função, não apenas no campo econômico, mas também no social e no político" (GRAMSCI, 1982, p. 3 e 4). Os camponeses, trabalhadores urbanos, sindicalistas e professores criam os seus intelectuais; a burguesia e a pequena burguesia fazem o mesmo.

Foucault (1999), do mesmo modo que Gramsci, muito embora com filiação filosófica e política diferente, também definiu o autor produtor de discursos como um indivíduo que, afinal de contas, não é neutro nem desprovido de interesses porque, regra geral, está comprometido com um projeto, com a sua coerência e com a sua temática. O rigor teórico e metodológico, isto é, a disciplina com a qual nos brinda em seus escritos, e com a qual às vezes nos encanta, não é parte de um "sistema anônimo à disposição de quem quer ou pode servir-se dele, sem que seu sentido ou sua validade estejam ligados a quem sucedeu ser seu inventor" (FOUCAULT, 1999, p. 30). Foucault sequer se esquece dos comentaristas dos textos originais, na medida em que também eles têm os seus comprometimentos. Esses, diz-nos, insistem em repetir ad nauseam o "que estava articulado silenciosamente no texto primeiro" (FOUCAULT, 1999, p. 25).

Essa repetição em um enquadramento teórico marxista adquire grande importância. Para Gramsci, a repetição resulta de todo "movimento cultural que pretende substituir o senso comum e as velhas concepções de mundo" (GRAMSCl, 2006, 110). A repetição, no entanto, para não cansar e perder a sua força didática de agir, ao promover a concretização dos seus objetivos, o faz com diferentes estilos e formas literárias.

A construção de um Estado da Arte ou Estado do Conhecimento que pretende ser crítico não pode, portanto, resultar em um simples e "inofensivo" inventário. Para ter potência política e social de transformação, antes de contabilizar textos e autores ou locais de produção, urge ter como objetivo 
trazer à luz as concepções de mundo que os seus autores e comentaristas pretendem cimentar e unificar em todo um bloco social. Para não ser um simples exercício para expor essas concepções, analisá-las ou lhes revelar as suas origens epistemológicas, ou os lugares de produção, há de lhes captar o sentido do movimento que fazem, o seu impacto em termos de construção de novos tempos e as alterações que são capazes de promover para privilegiar as concepções que elegem.

Assim, um Estado da Arte que tenha como objeto a reforma das universidades brasileiras carece ter como objetivo a transformação da realidade, explicitando claramente as concepções de reformas que se pretende realizar, principalmente em um momento de grande reestruturação do capital mundial, quando, inclusive, já se fala em uma Sociedade e em uma Economia do Conhecimento, ou como Lima e Contel (2011, p. 93) preferem: uma "geopolítica do conhecimento, capaz de envolver a distribuição de infraestrutura, atores e fluxos gerados pelas atividades intensivas em conhecimento, no contexto da internacionalização da educação superior atual”. Na Reunião Interministerial de Inovação e Conhecimento, por exemplo, ocorrida em Estoril (Portugal), em novembro de 2009, com a presença de ministros de Estado da região ibero-americana, diretamente ligados ao desenvolvimento da Ciência, Tecnologia e Ensino Superior, os novos afazeres das universidades e de outros agentes da inovação e do conhecimento foram explicitados com a intenção de:

Reforçar os programas de inovação no quadro das estratégias nacionais de desenvolvimento dos respectivos países, em políticas públicas de longo prazo, dirigidas aos agentes da inovação e do conhecimento (empresas, principalmente pequenas e médias empresas, universidades, centros de I\&D, centros de pós-graduação, empresas de base tecnológica, parques científicos e tecnológicos, organismos da administração, redes de inovação sócio produtiva e setores sociais) para o estímulo da apropriação social generalizada da cultura científica e tecnológica (OEI, 2009).

As autoridades reunidas em Estoril não se descolam das autoridades do Banco Mundial (BM) e da própria Organização das Nações Unidas para a Educação, a Ciência e a Cultura (UNESCO), para as quais há a mesma necessidade de ações de reforço aos programas de inovação, ciência e tecnologia, de modo a adaptá-los às mais imediatas demandas do capital. Segundo o Relatório de Desenvolvimento Mundial 1998-1999 do BM “o conhecimento é a chave, e não o capital, para o crescimento econômico sustentado e meIhorias no bem-estar humano" (BANCO MUNDIAL, 2000). O conhecimento, destarte, passa a ter lugar importante e central no processo de acumulação mundial, chegando mesmo a deslocar o capital de seu lugar tradicional. As universidades, em tal perspectiva, precisam, então, ser reformadas para se constituírem como lócus privilegiados para essa produção de conhecimentos importante para o capital.

As reformas das universidades e demais centros de pesquisas brasileiros parecem se subordinar a essa pauta se esforçando para atingirem status de centros de produção de conhecimento, em especial de dois tipos: conhecimentos tecnológicos - isto é, conhecimentos técnicos ou simplesmente know-how, e conhecimentos sobre produtos, processos e instituições. Outras funções sociais mais ligadas às demandas dos seus contextos regionais tendem a ser secundarizadas ou mesmo menosprezadas. O que importa, como projeto de futuro, é a produção de conhecimentos em atenção às demandas internacionais de produção e acumulação do capital e, por conseguinte, a inserção produtiva das universidades e centros de inovação e desenvolvimento em um mundo globalizado comprador e vendedor de conhecimentos com alto valor agregado. Observe-se que a inserção das 
universidades nessa divisão internacional da produção científica atende, sobretudo, ao capital, pouco se importando com as demandas nacionais de desenvolvimento sustentável para os seus habitantes.

É, em face disso que um Estado da Arte ou do Conhecimento, em uma perspectiva crítica diferente das perspectivas quantitativistas que predominam, precisa assumir o desafio de apreender a essência dos textos produzidos sobre a reforma da universidade e tratá-los como peças ideológicas. Urge situá-los conforme os acontecimentos históricos que lhes dão origem e evidenciar os momentos em que se inscrevem e qual sociabilidade promovem.

\section{OBJETo de InVESTigaÇão}

A investigação em curso definiu como objeto os textos científicos que tratam da reforma da universidade no Brasil exclusivamente veiculados em periódicos científicos. Foi uma opção metodológica a restrição a eles, mesmo sabendo haver grande difusão científica por meio de outros veículos como os livros, por exemplo. É grande a limitação que impossibilita abarcar todos os textos; contam-se aos milhares as publicações encontradas em bancos de dados e ferramentas de buscas, por exemplo, no Google Acadêmico. É, pois, impossível, como afirma Kosik (1976, p. 44), oferecer "um quadro total da realidade, na infinidade dos seus aspectos e propriedades". É tal a nossa barreira que fomos forçados a optar pela construção de um conjunto de textos estruturados como um todo que possa ser dialeticamente compreendido.

O estudo da reforma universitária, por si mesmo, não é coisa simples. Em princípio, toda reforma sempre pretende atingir a meIhor forma, os melhores consertos, modificações e incremento das suas atividades-fim, como ensino, pesquisa e extensão. Uma reforma, qualquer que seja, ainda pode variar de intensidade, indo de uma reforma superficial às alterações mais profundas e essenciais. Dois autores, Samper e Boaventura Santos, nos dão uma ideia de propostas de reformas das universidades e da complexidade que podem adquirir. Samper (2007) propõe criativas reformas da universidade em sete áreas: democratização do acesso a partir de uma avaliação crítica e rigorosa dos procedimentos de acesso, evitando-se a massificação; resgate da centralidade das atividades de bem-estar e serviço à comunidade; criação de modelos alternativos de investigação-ação-participação, com a reformulação dos nexos entre interesses científicos e sociais, e reorientação das atuais relações entre universidade-sociedade; rigorosa ecologia dos saberes que horizontalize os saberes acadêmicos e outros igualmente importantes para a sociedade; vigorosos vínculos da universidade com a educação básica; controle pela comunidade científica de sua agenda, mesmo nas relações entre indústria, produção e universidade; maior responsabilidade social como expressão da autonomia e liberdade acadêmica. Ademais, para Samper, tudo isso seria incompleto sem necessárias e importantes medidas institucionais, como nova institucionalidade universitária pública e regulação do setor universitário privado. Santos (2008), por sua vez, ao escrever sobre A Universidade no século XXI: para uma reforma democrática e emancipatória da Universidade, destaca o zelo reformista do Banco Mundial e as deficiências da universidade pública, acentuando que tal zelo incide contra o poder dos docentes e a liberdade acadêmica, devendo os docentes ceder lugar para administradores treinados e para o empresariamento da universidade. Ele acrescenta que o Banco Mundial se esforça junto aos países periféricos para que reduzam "o seu financiamento ao sector público e criem quadros legais que facilitem a expansão da educação superior privada enquanto complemento essencial da educação superior pública" (SANTOS, 2008, p. 30).

O exame dos textos científicos sobre a reforma da universidade no presente texto pouco se importará com o tamanho, intensidade e foco das reformas, entendendo que qualquer que seja produzirá impactos sobre as demais 
dimensões da universidade. O movimento de reforma é dialético e os seus elementos se determinam reciprocamente, criando novas sínteses. É, pois, forçoso estudá-lo em sua totalidade no contexto da sociedade em que ocorre. Os diferentes textos científicos em circulação no meio acadêmico, mesmo que abranjam um público restrito, são importantes instrumentos de facilitação, críticas etc. assim como são cimentadores e unificadores de determinadas concepções de universidade.

Em termos de objetivo geral a nossa intenção é, portanto, a de captar o sentido e o movimento real dessa produção intelectual em revistas científicas que toma como objeto a reforma da universidade no Brasil. O que ela critica e apoia? Que tipo de universidade quer cimentar? Que concepção ou concepções de universidade se propõe a naturalizar?

Nosso pressuposto é o de que a reforma das universidades, como vem sendo pretendida e realizada, aponta para uma universidade produtiva e eficiente, bem em consonância com a lógica e a retórica capitalista e neoliberal. Fora dos espaços governamentais e dos organismos internacionais, sabe-se mais sobre qual modelo de universidade é preciso obstar e combater renhidamente, do que sobre o modelo que atende aos anseios da sociedade brasileira e da comunidade científica em seu estágio de desenvolvimento.

\section{MÉTOdo DE INVESTIGAÇÃO}

O método de investigação utilizado assumiu elementos do Materialismo Histórico Dialético, como foi desenvolvido por Karl Marx ao longo de sua obra. O conjunto de textos encontrados nas revistas científicas em circulação no Brasil, América Latina e Caribe constituiu o seu ponto de partida. A operacionalização não poderia ser outra senão partir do concreto representado por esse conjunto de artigos para a apreensão de elementos ideológicos cada vez mais sutis, indo até a apreensão de suas determinações mais simples. Isto, sem dúvida, demandou idas e vindas analíticas, do concreto ao abstrato e do abstrato ao concreto, de modo a entender o conjunto de artigos não como uma representação caótica de um todo, mas como rica totalidade de múltiplas determinações e relações.

Tomando como objeto tais textos, cumprimos as etapas que o método impõe. A primeira etapa nos levou a identificá-los em periódicos científicos em circulação durante o período de 1993-2013, quando foram intensificadas as reformas dos Estados Nacionais da região. Essa etapa foi de constituição de um todo, cuja representação era caótica preliminarmente. Sua inventariação pura e simples apenas levou à quantificação sem qualquer captação de suas sutilezas, determinidades ou qualidades e relações.

Nesta etapa foram objeto de investigação os seguintes periódicos de circulação nacional com artigos diretamente relacionados ao objeto da investigação:

\section{Quadro 1 - Periódicos}

\begin{tabular}{|l|}
\hline Cadernos de Pesquisa \\
\hline Revista Gestão Universitária na América \\
Latina - GUAL \\
\hline Revista Avaliação \\
\hline Revista Educação \& Sociedade \\
\hline Revista Educação \& Pesquisa \\
\hline Revista Ensaio \\
\hline $\begin{array}{l}\text { Revista Iberoamericana de Educación de } \\
\text { la Organización de los Estados Iberoame- } \\
\text { ricanos }\end{array}$ \\
\hline Caderno CEDES \\
\hline Pro-Posições \\
\hline
\end{tabular}

Fonte: Elaboração dos autores.

Na etapa seguinte, os artigos inventariados foram objeto de exame, análise de conteúdo e de discurso por todos os componentes do Grupo de Pesquisa Políticas Públicas, Avaliação e Gestão, bem como, matéria de debates para fins de consolidação das análises. Como já afirmado, está distante de nós a ingenuidade de dar conta de todos os textos 
e dos seus conteúdos veiculados no período, seja em livros físicos e eletrônicos, na WEB e nos colóquios, seminários e congressos. Tampouco, tivemos a intenção de oferecer "um quadro total da realidade, na infinidade dos seus aspectos e propriedades" (KOSIK, 1976, p. 44).

A etapa derradeira foi a elaboração de sínteses, isto é, de unidades do múltiplo. Tais sínteses evidentemente contêm as determinações abstratas gerais encontradas nos textos constituintes do todo, que convêm mais ou menos aos diversos projetos de sociedade; categorias que articulam os textos e sobre as quais assentam os diferentes grupos interessados nas reformas das universidades; sínteses das propostas de reformas de universidades.

\subsection{O todo caótico}

O trabalho de identificar textos em periódicos científicos em circulação no período de 2003 a 2013 nos levou à constituição da seguinte tabela, onde se pode observar os totais de quantidades de textos por ano de publicação e veículo de publicação, considerando, ainda, a frequência de ocorrência dos textos pesquisados tanto em sua dimensão total (campo denominado FT - Frequência Total) como em sua dimensão de frequência por revista (campo denominado FR - Frequência por Revista). Esses dados encontram-se estruturados na tabela a seguir:

\section{Tabela 1 - Textos científicos publicados entre 2003-2013}

\begin{tabular}{|c|c|c|c|}
\hline Ano & FT & FR & Veículos de Divulgação \\
\hline 2003 & 1 & 1 & Avaliação \\
\hline 2004 & 14 & $\begin{array}{l}1 \\
9 \\
3 \\
1\end{array}$ & $\begin{array}{l}\text { Cadernos do Centro de Estudos Educação e Sociedade (CEDES) } \\
\text { Educação \& Sociedade: Revista de Ciências da Educação } \\
\text { Revista Iberoamericana de Educación do Centro de Altos Estudios Universi- } \\
\text { tarios de la Organización de Estados Iberoamericanos } \\
\text { Revista Pro-Posições da Fac. Educação da Unicamp }\end{array}$ \\
\hline 2005 & 7 & 7 & $\begin{array}{l}\text { Seminário Internacional “Reforma e avaliação da Educação Superior - ten- } \\
\text { dências na Europa e na América Latina”. (Os textos desse Seminário não } \\
\text { foram publicados nas revistas científicas com as quais estamos trabalhando. } \\
\text { Eles foram encontrados por meio da ferramenta Google de pesquisa na WEB. } \\
\text { Dada a importância deles nossa opção foi de incorporá-los ao nosso estudo.) }\end{array}$ \\
\hline 2007 & 4 & 4 & Revista Gestão Universitária na América Latina - GUAL \\
\hline 2008 & 2 & $\begin{array}{l}1 \\
1\end{array}$ & $\begin{array}{l}\text { Ensaio: Avaliaçãa e Políticas Públicas em Educação } \\
\text { Avaliação: Revista da Avaliação da Educação Superior }\end{array}$ \\
\hline 2009 & 3 & $\begin{array}{l}1 \\
1 \\
1\end{array}$ & $\begin{array}{l}\text { Ensaio: Avaliação e Políticas Públicas em Educação } \\
\text { Revista Iberoamericana de Educación } \\
\text { Avaliação: Revista da Avaliação da Educação Superior }\end{array}$ \\
\hline 2010 & 8 & $\begin{array}{l}2 \\
1 \\
1 \\
4\end{array}$ & $\begin{array}{l}\text { Educação e Pesquisa: Revista da Fac. de Educação da USP } \\
\text { Ensaio: Avaliação e Políticas Públicas em Educação } \\
\text { Avaliação: Revista da Avaliação da Educação Superior } \\
\text { Revista Gestão Universitária na América Latina - GUAL }\end{array}$ \\
\hline 2011 & 10 & $\begin{array}{l}2 \\
8\end{array}$ & $\begin{array}{l}\text { Educação e Pesquisa: Revista da Fac. de Educação da USP } \\
\text { Revista Gestão Universitária na América Latina - GUAL }\end{array}$ \\
\hline 2012 & 13 & $\begin{array}{l}1 \\
12\end{array}$ & $\begin{array}{l}\text { Ensaio: Avaliação e Políticas Públicas em Educação } \\
\text { Revista Gestão Universitária na América Latina - GUAL }\end{array}$ \\
\hline 2013 & 9 & $\begin{array}{l}1 \\
1 \\
7\end{array}$ & $\begin{array}{l}\text { Ensaio: Avaliação e Políticas Públicas em Educação } \\
\text { Avaliação: Revista da Avaliação da Educação Superior } \\
\text { Revista Gestão Universitária na América Latina - GUAL }\end{array}$ \\
\hline Total & 71 & 71 & \\
\hline
\end{tabular}

Fonte: Elaboração dos autores. 
O conjunto constituído por esses 71 textos foi construído empiricamente a partir de busca nos veículos de publicação científica indicados. É uma quantidade que corresponde a uma média de produção equivalente a 7,1 textos por ano, o que é pequena frente à importância e relevância da temática. Lima e Contel (2011, p. 15) também observaram que “em âmbito nacional, há relativamente pouca informação acerca de investigações realizadas por pesquisadores isolados".

O mesmo conjunto de textos nos esclarece pouco, porque apenas nos informa os anos, quantidades e veículos de publicação. Absolutamente não temos consciência do que os seus textos veiculam essencialmente; na perspectiva da pseudoconcreticidade nada mais é do que um claro-escuro de verdade e engano. Segundo afirmação de Kosik, "seu elemento próprio é o duplo sentido. O fenômeno mostra a essência e, ao mesmo tempo, a oculta" (1976, p. 14). Ele é para nós o que Marx denominou de um "todo caótico", mas sem que haja falta de algum tipo de ordem em seu interior; o que apresenta é uma nebulosidade que nos impede apreender a sua essência. Com efeito, se quisermos conhecê-lo, é preciso que realizemos o "détour" do qual Kosik nos fala, indo das partes ao todo e daí a inúmeras voltas às partes. Idas e vindas são determinações do método do materialismo-histórico. É a sua dialética que nos move do concreto ao abstrato, e deste ao concreto tantas vezes quanto necessárias. Essa é a condição para apreender em todos os planos e dimensões a realidade objetiva que esse conjunto caótico de textos constrói.

\section{Reforma da Educação Superior no BRASIL}

Na literatura veiculada no período 20032013 há blocos e sub-blocos de autores que se alinham em posições diferentes, nomeadamente quando estudam as reformas da educação superior no Brasil identificando causas, motivações e desdobramentos.
Inicialmente, há que se destacar um primeiro bloco de textos que Foucault (1999, p. 30) diria estarem "ligados a quem sucedeu ser seu inventor". Ele é formado de textos produzidos por quadros partidários e governamentais encarregados de disseminar e obter consenso favorável à reforma da educação superior no Brasil e em países vizinhos. Esse bloco é constituído pelos textos de Genro (2005), Brovetto (2005), Trindade (2005), Mota (2005) e Pacheco \& Ristoff (2005); eles, claramente, se constituem como comentaristas das intenções governamentais. Genro (2005, p. 10), por sua situação fora "do esquema ultraliberal adotado por uma série de outras reformas feitas nos anos 90", "no contexto de um novo modelo de desenvolvimento e de paz social duradoura pela inclusão e pelo crescimento econômico sustentado", expõe a reforma como "um modelo que combina a estabilidade macroeconômica com políticas públicas corajosas e ousadas de largo alcance histórico e de grande abrangência social". O texto de Brovetto (2005), ex-Ministro da Educação do Uruguai, clama por reformas da educação superior na América Latina, sugerindo que contenham uma nova proposta educativa importante para a formação, para o desconhecido futuro e que seja para todos ao longo da vida. O texto de Trindade (2005) insiste em saturar de historicidade a reforma da educação superior e exaltar a necessidade de ser avaliada continuamente. Mota (2005) exalta e conclama a participação da sociedade na elaboração e concretização da reforma. Pacheco \& Ristoff (2005), dois importantes quadros político-administrativos brasileiros, expõem as suas crenças na importância da reforma para a construção do futuro dada a sua capacidade de ir além do Programa Universidade para Todos (Prouni), criar novas universidades, ampliar o corpo docente das universidades públicas, aprovar o plano de carreira dos funcionários públicos técnico-administrativos das instituições federais de educação superior, democratizar o acesso ao conhecimento e consolidar o novo Sistema Nacional de Avaliação da Educação Superior 
(SINAES). Mais de dez anos depois da retórica desses dois autores, as universidades federais ainda reivindicam autonomia de gestão financeira prevista na Constituição, dotação global de recursos, irredutibilidade nos repasses e continuada capacidade de expansão. Chama a atenção no texto de Pacheco \& Ristoff a apologia à avaliação das universidades e a ausência de qualquer restrição à dominação simbólica dos instrumentos avaliativos. Afinal, como há muito se sabe esses instrumentos também não são neutros ou desprovidos de forças de conformação. O claro interesse presente nos textos de todos autores brasileiros citados é então o de tornar consensual a proposta de reforma oriunda do governo. Eles, por conseguinte, se exibem como um bloco com grande força histórica.

Um segundo bloco prontamente identifica as reformas com as demandas nacionais, resultantes do desenvolvimento do país. São integrantes desse bloco os textos de Corbucci (2004), Pires (2004), Mancebo (2004), Trindade (2004). Corbucci (2004), logo na introdução, admite a eclosão das reformas como necessidade de democratização do acesso à educação superior e de inserção da universidade no projeto de desenvolvimento nacional. Pires (2004, p. 43) as vê como necessárias dado o redesenho do Estado em face à crise fiscal e à avidez empresarial de maximização de lucros, a partir do oferecimento da educação "como simples prestação de serviços". Mancebo (2004) a apresenta como derivação da ação reformista induzida pelo MEC em consonância com as propostas de diversas entidades em seus fóruns próprios. Com mais historicidade, Trindade (2004) vê a reforma das universidades como continuidade da tradição de Córdoba e das mobilizações universitárias no Brasil (1960-1963) em um contexto nacional de redemocratização com capacidade de envolver a comunidade universitária, as entidades representativas e os setores organizados da sociedade civil.

Em um ponto de vista similar, identificamos um terceiro bloco de textos escritos por Aragunde (2011), Falqueto \& Farias (2013) e
Suasnábar (2005). Seus autores abandonam a perspectiva de totalidade e se atêm às relações locais e nacionais, como se os lugares de onde falam não tivessem ações de reciprocidade com o estrangeiro. $\mathrm{O}$ que une tal bloco de textos é a defesa da educação superior como bem público e direito básico e universal dos cidadãos, como estratégia para reduzir as desigualdades sociais e regionais e construção de uma nação soberana, democrática e inclusiva. Em tais textos, encontra-se a defesa da universidade pública gratuita, de qualidade e referência, com necessidade de ser fortalecida para promover inclusões, com a condição de ser bem avaliada e regulada pelo Estado, vinculada a outros níveis de ensino e expandida até o interior.

Um quarto bloco, constituído ainda que por um único texto, entende que as reformas são resultantes de uma vocação reformista desenvolvida pela educação superior na América Latina a partir da década de 1990 (VARGAS, 2012). Destacar esse único texto se justifica pelo fato de estar considerando a universidade e sua vocação reformista sem quaisquer relações de exterioridades locais, nacionais e internacionais, como se tal vocação decorresse tão-somente das atividades dos sujeitos acadêmicos no interior da universidade. Seu foco metodológico na singularidade leva a autora a considerar as questões isoladas mais aparentes e pontuais. A universidade em sua perspectiva é uma instituição sem mediações. Tudo em seu interior deriva de problemas criados endogenamente pelos sujeitos que vivem o dia a dia do ensino, pesquisa, extensão e administração. A reforma da universidade responde aos problemas mais emergentes a partir das relações desenvolvidas cotidianamente. Ao fim, os sujeitos são a fonte dos problemas, devendo eles próprios ser responsabilizados por isso.

Um quinto bloco, bastante crítico das reformas fundadas na doutrina neoliberal, constitui-se de textos em que as reformas são percebidas como partes de um todo. Aparecem articuladas às transformações mundiais, mas sem que isto tenha o significado de abranger 
todas as relações da realidade objetiva local, nacional e internacional. Regra geral, contêm denúncias à passividade e aceitação do Estado nacional brasileiro às determinações estrangeiras. Representam bem esse bloco os textos de Bertolin (2011); Galleguilos \& Catani (2011); Wielewicki \& Oliveira (2010). Para Bertolin (2011, p. 239), a reforma da educação superior no Brasil "está ligada às orientações de organismos internacionais a Estados Nacionais que, sob a justificativa de maximizar os benefícios sociais dos sistemas educacionais têm implantado reformas baseadas em lógicas de mercado e serviço comercial". Na mesma linha se apresentam os textos Hermo \& Verger (2010), Santos (2010), Borges \& Aquino (2013). Ora, situar os organismos internacionais como principais indutores das reformas no Brasil talvez seja o maior problema teórico e metodológico desse bloco de produção analítica, não obstante toda a sua importância e relevância. Está claro em todos os textos a atuação determinante de tais organismos nos rumos da educação nacional em termos gerais e no modo como o país se relaciona com ele. Para Cunha (2005), que faz severas críticas a esse tipo de abordagem, "esta concepção é pequena, nos coloca como vítimas, como se este [o Brasil] fosse um pequeno Pais". Ele argumenta que a presença externa em projetos educacionais brasileiros não é uma determinação unilateral, de fora para dentro; ela ocorre em sintonia com as políticas públicas desenvolvidas internamente, e jamais como determinantes delas. Florestan Fernandes, em sua clássica obra "Capitalismo Dependente e Classes Sociais na América Latina” (1975), concorda com Cunha, quando se constata a reciprocidade de interesses entre elites externas e nossas elites econômicas, políticas e culturais. Apesar das históricas rupturas nessa reciprocidade, não é difícil identificar os endossos a interesses das nossas elites. Ressalve-se, porém, que os textos representativos desse quarto bloco, a despeito de quaisquer problemas, ainda assim têm grande importância e relevância. A grande contribuição deles é a exposição dos mecanismos desnacionalizantes dos agentes internacionais do capital e das implicações da incorporação de aspectos neoliberais na reestruturação dos Estados Nacionais.

Mais um bloco de textos, o sexto, também sobressai com características bastante peculiares; ele é veiculado predominantemente pela Revista GUAL, editada pelo Instituto de Pesquisas e Estudos em Administração Universitária da Universidade Federal de Santa Catarina - INPEAU. É acentuada a sua tendência de apresentar propostas de intervenções no sistema de gestão da universidade (RICHARTZ, KRÜGER, BORGERT \& PETRI, 2012; PICCHIAI, 2012; ROJAS, JULIATTO, FRANCHINI, 2011; VARGAS \& ESTRADA, 2013; SCHARMACH, DOMINGUES, CARVALHO \& MACHADO, 2012). Chama a atenção a abordagem que seus autores fazem dos problemas da universidade, focalizando aspectos pontuais que devem ser objeto de intervenções para o melhoramento da qualidade e eficiência, desprovidos, porém, de qualquer perspectiva de totalidade. A limitação a aspectos pontuais ou particulares parece indicar o desenvolvimento ou aperfeiçoamento de instrumentos para o incremento de determinadas dimensões da universidade e criação de mercado para eles próprios, os seus autores. A focalização em determinados aspectos desconsidera a complexidade da universidade, suas relações e os grandes interesses que estão em jogo.

Um sétimo bloco é composto por dois autores: Dale (2004) e Amaral (2010). A principal característica presente é a predominância de uma visão de totalidade, ainda que seus autores estejam em diferentes pontos de observação. Dale (2004, p. 455), situado em um ponto de observação mais ao alto, como se estivesse em um mirante, e com as determinações formativas próprias de seu olhar, situa as reformas em uma "Agenda Globalmente Estruturada para a Educação". Ele argumenta que as reformas não estão descoladas das mudanças da "natureza das forças globais". Essas forças, muitas delas de ordem econômica, operam supra e transnacionalmente, 
rompendo fronteiras nacionais para construir/reconstruir relações entre as nações. Os Estados Nacionais, do lugar de onde observa, interpretam e respondem aos movimentos que fazem, adequando a elas, ou não, as suas instituições de educação superior. Para ele, a globalização comporta "um conjunto de dispositivos político-econômicos para a organização da economia global, conduzido pela necessidade de manter o sistema capitalista, mais do que qualquer outro conjunto de valores". Os Estados Nacionais, em função de pressões econômicas e de interesses próprios, são mais ou menos aderentes aos seus valores. Dale (2004, p. 438) confirma a argumentação de Cunha, a qual já destacamos. Para ele a globalização, considerando-se particularmente os seus valores, é uma inspiração para os Estados Nacionais; não é "uma estrutura que molda as suas respostas e a seleção dos recursos". Os quadros interpretativos dos Estados Nacionais é que são os produtores das respostas e dos recursos a utilizar, observando-se que "nem todos os efeitos globalmente iniciados serão mediados pelo Estado". Como diria Florestan Fernandes, já mencionado, nem sempre há reciprocidade de interesses entre as elites externas e as nossas elites econômicas, políticas e culturais.

O texto de Amaral (2010, p. 39) propõe que as reformas da educação superior sejam examinadas em um contexto diferenciado. Seu argumento básico é que elas "não podem ser compreendidas inteira e exclusivamente a partir da perspectiva nacional". Há novos contextos sociais, políticos e econômicos determinados pelos níveis de organização e integração internacional que impactam as dinâmicas de inter-relações globais. O autor, ao longo do texto, critica os limites da teoria neoinstitucionalista que se foca na difusão de padrões e normas universalizados e nas suas relações com o comportamento social; também faz críticas à teoria da externalização, porquanto sobreleva a lógica interna dos sistemas com prejuízos dos argumentos sobre os efeitos de processos institucionais. São essas críticas que o levam a acatar a teoria do re- gime internacional, elaborada a partir de John Ruggie, Stephen Krasner, M. Finnemore. A simpatia de Amaral (2010, p. 41) pela última o leva imediatamente a considerá-la como "ferramenta teórica útil na análise da dimensão internacional das políticas educacionais", particularmente por haver na formação do regime internacional forte "convergência das expectativas dos participantes" que, segundo afirma, ocorre a partir de participação em estudos internacionais, programas de estatísticas mundiais, conferências mundiais etc. As organizações internacionais e os atores nacionais em tal processo de convergência têm papéis destacados, cabendo aos últimos explicitar e dar forma aos interesses e às preferências nacionais. É sobre essa convergência de expectativas que ocorre, então, a construção de um regime internacional de educação superior e, por conseguinte, das suas reformas. Conclusivamente, Amaral (2010, p. 50) afirma não ser, portanto, por acaso a implementação das mesmas reformas em escala global, todas elas caracterizadas pela focalização no output, introdução do paradigma da eficiência e eficácia, mecanismos de mercado, avaliação e benchmarking, e descentralização da gestão.

\section{UMA SÍNTESE}

O objetivo do presente texto foi o de iluminar as determinações abstratas gerais encontradas nos textos constituintes do todo, que convém mais ou menos aos diversos projetos de sociedade. O interesse particular, portanto, foi o de avultar as possibilidades de reforma da educação superior exibidas. Em outras palavras, tratou-se de destacar em que situação se encontra o entendimento de reforma da educação superior e para qual horizonte aponta.

O governo brasileiro, desde 2004, apresentou o seu projeto de reforma da universidade e da educação superior brasileira. Os textos do primeiro bloco, em seu conjunto, construídos por autores ligados direta ou indiretamente a ele, buscam a formação de um consenso em torno dessa proposta que, em 
essência, tenta adequar a universidade e a educação superior a um novo modelo de desenvolvimento e de paz social, com inclusão e crescimento econômico sustentável. A educação superior seria importante para todos ao longo da vida e para a formação para o desconhecido. A universidade, o local privilegiado dessa educação, teria garantia de autonomia de sua gestão financeira, recursos necessários, irredutibilidade dos repasses e expansão contínua. A sociedade seria coparticipante em todos os momentos da reforma.

A sociedade, principalmente a Academia, está, no entanto, distante de um consenso. A dispersão dos diferentes textos que tratam da temática reforma da universidade e da educação superior nos periódicos de divulgação científica nos dá a dimensão da arbitrariedade ideológica que expressam. Para quatro blocos de textos - segundo, terceiro, quarto e quinto - é preciso de fato reformar a universidade que aí está. Para uns seria suficiente a superação de problemas pontuais imediatos. Para outros bastaria superar as causas das tensões e das contradições que os sujeitos acadêmicos e a própria instituição desenvolvem. O maior bloco de textos concorda ser imperativo expurgar do mundo da educação superior as medidas e ações provenientes da doutrina neoliberal, emanadas de organismos internacionais.

É identificável em alguns textos certa concepção ideológica que nem sempre é clara e deixa transparecer um ideal de conservação da universidade como existe, apenas admitindo-se algumas reformas que não a alterem substantivamente. O objetivo, como diria Gramsci, parece o de preservar o que está cimentado e unificado em conformidade com as suas concepções ideológicas, as quais comportam um dado modelo de universidade. $E$ esse modelo não seria superado. Parafraseando Gramsci (1999, p. 99), se poderia afirmar que excepcionalmente imprimiriam às suas reformas um ritmo tão lento e metódico que elas poderiam passar despercebidas pela sociedade como um todo.

Os textos, como uma concepção mais ampliada de reforma da universidade e da educação superior, foram formulados por autores situados no ponto mais ao alto de um metafórico mirante de observação. Para estes, reformar a universidade, para inseri-la no contexto da globalização, não é uma determinação que provém dela; a globalização é antes uma inspiração e os movimentos de inserção da universidade em seus limites devem ocorrer com a mediação da sociedade e do Estado. Se somente são consideradas as perspectivas nacionais, há riscos evidentes de isolamento do país, de atrasos importantes para as nossas universidades. A tarefa que nos cabe, segundo dizem, é fazer convergir os nossos interesses e preferências nacionais com os da globalização.

As determinações mais abstratas que emergem dos textos e que reagem à proposta do governo brasileiro tendem a conservar determinado modelo de universidade e assumem a importância de não se descuidar dos movimentos que caracterizam a globalização e as reformas do Estado em bases neoliberais. A reação é bem maior que a proposição. Há apenas tênues e vagas insinuações apontando para uma nova universidade, quem sabe em consequência de uma compreensão ainda limitada do conjunto universitário, dos seus fins essenciais, das relações que lhes são próprias e da sua importância para o projeto de sociabilidade do país. Talvez isso possa justificar a carência de estudos que compreendam a universidade e a educação superior para além dos limites históricos do lluminismo.

Ora, a produção científica é vital no processo de reforma da universidade e da educação superior. Como Gramsci já sinalizou, os textos científicos tanto aperfeiçoam "os próprios instrumentos de experiência e de sua verificação", quanto também podem determinar o "que é arbitrário, individual, transitório" (2006, p. 173). Antes de expressarem ideologias particulares, eles têm o poder de organizar a comunidade acadêmica, dando formas ao campo de atuação, conscientização e luta; se são apenas veiculação de ideologias arbitrárias "não criam mais do que "movimentos" individuais, polêmicas etc.” (1999, p. 237). 
O conjunto de textos analisados mostra a formação de blocos com grande força para organizar a comunidade acadêmica e a própria sociedade, ainda que entre eles possa haver movimentos de pequenos grupos acentuadamente polêmicos. Seus autores são intelectuais comprometidos com dada concepção de mundo que se incumbem de promover as ligações entre a teoria e a prática. São especialistas em produzir determinadas necessidades para substituir ou manter o senso comum e emancipar a sociedade, ou não, de velhas concepções. Daí não se cansarem de socializar os seus argumentos ainda que com formatos diferentes; Gramsci nos diz que a repetição e o meio didático são eficazes para agir sobre as mentalidades, assim como, o indispensável trabalho incessante ao estabelecimento de um consenso ativo.

As direções que apontam são várias, assim como a sociabilidade que pretendem preservar, reformar e hegemonizar. Nos dizeres de Gramsci (1999, p. 97), "a escolha e a crítica de uma concepção de mundo são, também elas, fatos políticos".

\section{REFERÊNCIAS}

AMARAL, M. P. Política pública educacional e sua dimensão internacional: abordagens teóricas. Revista Educação e Pesquisa, São Paulo, v. 36, n. especial, p. 039-054, 2010.

ARAGUNDE, R. Realineamiento universitario en la isla de Puerto Rico. Revista Gestão Universitária na América Latina, Florianópolis, v. 4, n. 1, p.82-109, jan./fev./mar./abr. 2011.

BANCO MUNDIAL. Relatório de Desenvolvimento Mundial (1998-1999). Disponível em: <http:// web.worldbank.org/>. Acessado em: 23 nov. de 2013.

BERTOLIN, J. C. G. Os quase-mercados na educação superior: dos improváveis mercados perfeitamente competitivos à imprescindível regulação do Estado. Revista Educação e Pesquisa, São Paulo, v. 37, n. 2, p. 237-248, mai./ago. 2011.

BORGES, V. M. O.; AQUINO, E. T. Ensino superior à ordem do capital internacional. Revista Gestão Universitária na América Latina, Florianópolis, v. 6, n. 2, p. 22-32, abr. 2013.

BROVETTO, J. Los nuevos desafíos en educación superior en América Latina. In: GENRO, T. Seminário Internacional "Reforma e avaliação da Educação Superior - tendências na Europa e na América Latina”, São Paulo, 25 de abril de 2005. Brasília: Instituto Nacional de Estudos e Pesquisas Educacionais Anísio Teixeira, 2005, p. 19-28.

BRZEZINSKI, Iria; GARRIDO, Elsa. Estado da arte sobre a formação de professores nos trabaIhos apresentados no GT 8 da ANPEd (1990-1998). In: REUNIÃO ANUAL DA ANPEd, 22, 1999, Caxambu, MG. Anais... Caxambu, MG: ANPEd, 1999. 1 CD-ROM.

CORBUCCI, P. R. Financiamento e democratização do acesso à educação superior no Brasil: da deserção do estado ao projeto de reforma. Revista Educação e Sociedade, Campinas, v. 25, n. 88, p. 677-701, Especial - Out. 2004.

CUNHA, L. A. Influências do FMI e Banco Mundial. Jornal Folha Dirigida. Rio de Janeiro, 15/10/2005, Especial do Dia do Professor, 2005. 
DALE, R. Globalização e educação: demonstrando a existência de uma "cultura educacional mundial comum" ou localizando uma "agenda globalmente estruturada para a educação"? Revista Educação e Sociedade, Campinas, v. 25, n. 87, p. 423-460, mai./ago. 2004.

DOS SANTOS, A. F. T. Política educacional para a "universidade microondas": gestão universitária, trabalho docente e qualidade da formação humana sob o efeito do "mercado educador”. Revista Gestão Universitária na América Latina, Florianópolis, v. 3, n. 1, 2010.

FALQUETO, J. M. Z.; FARIAS, J. S. A trajetória e a funcionalidade da universidade pública brasileira. Revista Gestão Universitária na América Latina, Florianópolis, v. 6, n. 1, p. 22-41, jan. 2013.

FERREIRA, Norma Sandra de Almeida. As pesquisas denominadas "estado da arte". Educ. Soc. [on-line], 2002, v. 23, n. 79, p. 257-272.

FIORENTINI, D. Rumos da pesquisa brasileira em Educação Matemática: O caso da produção científica em cursos de Pós-Graduação. Tese (Doutorado) - Faculdade de Educação da UNICAMP, Campinas, 1994.

FOUCAULT, M. A Ordem do Discurso. São Paulo: Edições Loyola, 1999.

GALLEGUILLOS, T. G. B.; CATANI, A. M. Avaliação da educação superior no Brasil e a expansão da educação superior em enfermagem. Revista Educação e Pesquisa, São Paulo, v. 37, n. 4, p. 843-860, dez. 2011.

GENRO, T. Seminário Internacional “Reforma e avaliação da Educação Superior - tendências na Europa e na América Latina", São Paulo, 25 de abril de 2005. Brasília: Instituto Nacional de Estudos e Pesquisas Educacionais Anísio Teixeira, 2005.

GRAMSCI, A. Cadernos do Cárcere. Rio de Janeiro: Civilização Brasileira, 1999.

GRAMSCI, A. Os Intelectuais e a Organização da Cultura. Rio de Janeiro: Civilização Brasileira, 1982.

HERMO, J. P.; VERGER, A. Educación superior: un estudio comparado entre el proceso de Bologna y el Mercosur. Revista Gestão Universitária na América Latina, Florianópolis, v. 3, n. 1, 2010.

KOSIK, K. Dialética do concreto. Rio de Janeiro: Paz e Terra, 1976.

LIMA, M. C.; CONTEL, F. B. Internacionalização da Educação Superior: nações ativas, nações passivas e a geopolítica do conhecimento. São Paulo: Alameda, 2011.

MANCEBO, D. Reforma universitária: reflexões sobre a privatização e a mercantilização do conhecimento. Revista Educação e Sociedade, Campinas, v. 25, n. 88, p. 845-866, Especial - Out. 2004 .

MARX, K. O capital - crítica da economia política. São Paulo: Editora Nova Cultural, 1996.

MEGID, J. N. Tendências da pesquisa acadêmica sobre o ensino de ciências no nível fundamental. Tese (Doutorado) - Faculdade de Educação da UNICAMP, Campinas, 1999. 
MOTA, R. A construção participativa do anteprojeto de reforma da educação superior do Brasil. In: GENRO, T. Seminário Internacional "Reforma e avaliação da Educação Superior - tendências na Europa e na América Latina”, São Paulo, 25 de abril de 2005. Brasília: Instituto Nacional de Estudos e Pesquisas Educacionais Anísio Teixeira, 2005, p. 37-46.

ORGANIZAÇÃO DE ESTADOS IBERO-AMERICANOS. Declaração da I Reunião Interministerial Ibero-americana de Inovação e Conhecimento realizada em Estoril, nos dias 9 e 10 de novembro de 2009. Disponível em: <http://segib.org> Acessado em: 23 nov. de 2013.

PACHECO, E.; RISTOFF, D. Construindo o futuro. In: GENRO, T. Seminário Internacional "Reforma e avaliação da Educação Superior - tendências na Europa e na América Latina”, São Paulo, 25 de abril de 2005. Brasília: Instituto Nacional de Estudos e Pesquisas Educacionais Anísio Teixeira, 2005, p. 45-51.

PICCHIAI, D. O plano de desenvolvimento institucional e o projeto pedagógico institucional de universidades públicas: limites organizacionais. Revista Gestão Universitária na América Latina, Florianópolis, v. 5, n. 3, p. 23-45, dez. 2012.

PIRES, V. Ensino superior e neoliberalismo no Brasil: um difícil combate. Revista Educação e Sociedade, Campinas, v. 25, n. 86, p. 263-268, abr. 2004.

RICHARTZ, F.; KRÜGER, L. M.; BORGERT, A.; PETRI, S. M. O balanced scorecard como ferramenta de gestão estratégica em uma universidade federal. Revista Gestão Universitária na América Latina, Florianópolis, v. 5, n. 3, p. 01-22, dez. 2012.

ROJAS, R. S. B.; JULIATTO, D. L.; FACCHINI, E.; PEREIRA, R. P. Utilização da metodologia BPM para adequação de um sistema de gestão integrada e retenção de conhecimento em uma instituição pública de ensino superior. Revista Gestão Universitária na América Latina, Florianópolis, Edição especial, p. 115-132, 2011.

SAMPER, S. de Z. Universidad, Crisis y Nación em América Latina. Revista de Estudios Sociales. Bogotá, Colombia, n. 26, 2007, p. 148-157.

SANTOS, B. S. A Universidade no Século XXI: Para uma reforma democrática e emancipatória da Universidade. In: SANTOS, B. S.; ALMEIDA FILHO, N. A Universidade no Século XXI: Para uma Universidade Nova. Coimbra, 2008. Disponível em: <http://www.boaventuradesousasantos. pt/>. Acessado em: abr. de 2014.

SCHARMACH, A. L. R.; DOMINGUES, M. J. C. S.; CARVALHO, C. E.; MACHADO, N. S. Avaliação das possibilidades de implantação do balanced scorecard em instituições de ensino superior. Revista Gestão Universitária na América Latina, Florianópolis, v. 5, n. 1, p. 250-272, jan./fev./mar./ abr. 2012.

SOARES, M. Alfabetização no Brasil - O Estado do conhecimento. Brasília: INEP/MEC, 1989.

SUASNÁBAR, C. Reforma de la Educación Superior y transformaciones en el campo académico en Argentina. Revista Pro-Posições, v. 16, n. 3, set./dez. 2005. 
TRINDADE, H. A república em tempos de reforma universitária: $\mathbf{O}$ desafio do governo Lula. Revista Educação e Sociedade, Campinas, v. 25, n. 88, p. 819-844, Especial - Out. 2004.

TRINDADE, H. Reforma e avaliação da educação superior. In: GENRO, T. Seminário Internacional "Reforma e avaliação da Educação Superior - tendências na Europa e na América Latina", São Paulo, 25 de abril de 2005. Brasília: Instituto Nacional de Estudos e Pesquisas Educacionais Anísio Teixeira, 2005, p. 29-36.

VARGAS, G. M. G. Educación superior pública en América Latina: características y desafíos. Revista Gestão Universitária na América Latina, Florianópolis, v. 5, n. 1, p. 216-227, jan./fev./mar./ abr. 2012.

VARGAS, G. M. G.; ESTRADA, F. R. Desafíos y problemáticas de la gestión universitaria en el sistema de la educación superior pública, aspectos a considerar en la región centroamericana. Revista Gestão Universitária na América Latina, Florianópolis, v. 6, n. 2, p. 231-258, abr. 2013.

WIELEWICKI, H. G.; OLIVEIRA, M. R. Internacionalização da educação superior: Processo de Bolonha. Revista Ensaio: Avaliação e Políticas Públicas em Educação, Rio de Janeiro, v. 18, n. 67, p. 215-234, abr./jun. 2010.

Submetido em: 13-7-2018

Aceito em: 8-10-2018 